\title{
PAPER
}

\section{Demographic and CT scan features related to cognitive impairment in the first year after stroke}

\author{
S M C Rasquin, F R J Verhey, R J van Oostenbrugge, R Lousberg, J Lodder
}

J Neurol Neurosurg Psychiatry 2004;75:1562-1567. doi: 10.1136/jnnp.2003.024190

See end of article for authors' affiliations

.....................

Correspondence to: Dr J Lodder, Department Neurology, PO Box 5800, 6200 MD Maastricht, the Netherlands;

¡lod@sneu.azm.nl

Received 23 July 2003

In revised form

23 January 2004

Accepted 23 January 2004
Objective: Little is known about the relation between stroke related features and cognitive performance over time when stroke patients with dementia or less severe cognitive disorders are considered separately. We aimed to study the features (computed tomography (CT) scan and demographic) that could be related to vascular cognitive impairment one, six, and 12 months after stroke.

Methods: A total of 176 patients with a first-ever brain infarct, a Mini Mental State Examination score $\geqslant 15$, age older than 40 years, and without pre-stroke dementia and other neurological or psychiatric disorders participated in this study. The following CT scan features were recorded: side of infarct, lacunar or territorial infarct, white matter lesions, silent infarcts, and brain atrophy. The demographic features studied were: age, level of education, and sex. Univariate and multivariate logistic regression analyses were performed to compare the three groups of patients (patients with dementia, patients with vascular cognitive impairment (VCI), and patients with vascular mild cognitive impairment $(\mathrm{MCl})$ ) with patients without cognitive disorders.

Results: At one month none of the variables were predictors of dementia; at six months older age (odds ratio (OR) 9.4), low education (OR 14.7), and territorial infarct (OR 10.6) predicted dementia; and at 12 months low education (OR 8.7) and pre-stroke cerebrovascular damage (OR 7.4) predicted dementia. Predictors of VCl were low education (OR 3.4) and territorial infarct (OR 2.4) at one month post stroke; older age (OR 4.3) and low education (OR 4.1) at six months; and older age (OR 3.5) at 12 months. Predictors of vascular $\mathrm{MCl}$ were low education (OR 4.96) and territorial infarct (OR 3.58) at one month; and older age and lower education at six months (OR 3.4 and 3.7, respectively) and at 12 months (OR 3.5 and 2.28, respectively).

Conclusions: Territorial infarct, older age, and low educational level are predictors of cognitive disorders after stroke.
$\mathrm{T}$ he risk of dementia and other cognitive disorders increases after stroke. Stroke contributes to the development of cognitive disorders in nearly $20 \%$ of elderly patients. ${ }^{12}$ Stroke related features such as multiple strokes, white matter lesions, left hemisphere infarct location, atrophy, and volume of infarcted tissue are associated with an increased risk of post-stroke dementia. ${ }^{3-11}$ Age and level of education have also been reported as risk factors for vascular dementia (VaD). ${ }^{7-9}{ }^{12}$ Traditionally, patients with VaD have been compared with non-demented stroke patients to detect associations between stroke related factors and cognitive disorders (usually dementia). As such cognitive disorders less severe than dementia were not considered. However, milder cognitive disorders are more likely to occur after stroke than VaD. ${ }^{13-17}$ These milder deficits, also called vascular mild cognitive impairment (MCI) or vascular cognitive impairment no dementia (CIND), may be barely perceptible in an early stage but may carry the risk of progression to more severe loss of cognitive functions. ${ }^{18-20}$ If vascular MCI is a transition phase in the development of dementia it is important to identify the specific risk factors for this to attempt to prevent the progressive decline in cognitive function..$^{21} 22$ The few studies that investigated risk factors for cognitive decline in patients with either vascular MCI or $\mathrm{VaD}$ found older age, educational level, volume of infarcted tissue, and left hemispheric infarct location to be associated with cognitive impairment after stroke. ${ }^{17}{ }^{23-26}$ However, these studies did not differentiate between patients with dementia and patients with less severe cognitive disorders. Consequently, mechanisms related to post-stroke cognitive disorders without dementia have not been identified.
In the present study, we distinguished between patients with dementia and those with cognitive disorders without dementia (vascular MCI). Since the subgroups of patients were defined on the basis of their cognitive performance, the subgroups were homogeneous and generalisations about risk factors for vascular cognitive impairment could be made for these groups. Because little is known about the influence of stroke related risk factors on the development of cognitive impairment over time, we also monitored the cognitive abilities of our patient sample over one year.

Our aim was to identify post-stroke predictors (stroke related and demographic) of VCI (with or without dementia) at 1,6 , and 12 months after stroke, with special emphasis on brain abnormalities as visualised by computed tomography (CT).

\section{PATIENTS AND METHODS Patient selection}

The Maastricht CODAS (COgnitive Disorders After Stroke) project is a prospective, observational study investigating the development of cognitive impairment after stroke, and identification of factors related to these disorders.

The study includes patients with a first-ever cerebral infarct who are older than 40 years (to exclude atypical stroke), have adequate post-stroke fluency in Dutch, and who have an initial Mini Mental State Examination (MMSE) $\geqslant 15$

Abbreviations: CODAS, COgnitive Disorders After Stroke; $\mathrm{Cl}$ confidence interval; $\mathrm{CT}$, computed tomography; $\mathrm{MCl}$, mild cognitive impairment; MMSE, Mini Mental State Examination; OR, odds ratio $\mathrm{VaD}$, vascular dementia; $\mathrm{VCl}$, vascular cognitive impairment 
(to ensure neuropsychological testing is possible). Exclusion criteria are severe aphasia and other neurological or major psychiatric disorders, which could lead to cognitive impairment other than the qualifying event. For this report patients with pre-stroke dementia were also excluded.

Consecutive stroke patients admitted to the University Hospital Maastricht or those who visited the outpatient neurological clinic between January 2000 and July 2001 participated in this study. During the inclusion period, 592 patients came to the hospital with a stroke. Of these 396 were excluded ( 89 were not first-ever strokes, 80 died within one month after stroke, 57 had a stroke located in the brainstem or cerebellum, 46 had MMSE $<15,35$ refused to participate, 34 had severe aphasia, 20 had other neurological or psychiatric disorders, 9 were younger than 40 years, 9 lived too far from the hospital, 6 were admitted too long after their stroke, 6 were in a coma, and 5 were not native Dutch speaking). A total of 196 patients were eligible for the CODAS study. Of these 18 had a haemorrhagic stroke and two patients had dementia before stroke and were consequently excluded.

Stroke was diagnosed by an experienced neurologist according to standardised, well accepted criteria described elsewhere. ${ }^{27}$ All patients had at least one brain CT scan. In most patients $(\mathrm{n}=93,52.9 \%)$, CT was performed at admission or one day later (median 1 day, range 0-150 days). If a patient had a second scan on which lesions were more clearly seen, this was used.

Patient data were entered into the Maastricht Stroke Register (MSR), a prospective databank containing clinical information of all stroke patients treated in the University Hospital Maastricht. ${ }^{27}$ The data included patient's age (high: 70 years and older, and low: younger than 70 years, based on the median split), sex, and level of education (low: primary education and vocational education, high: all other educational levels). All patients were tested neuropsychologically within one month of stroke (mean (SD) 1.07 (0.3) months), and again at six months (mean $6.06(0.41))$ and 12 months (mean $12.08(0.36))$. CT scanning was not repeated at follow up.

To define whether patients had a cognitive disorder, they were compared with a control group from the MAastricht Aging Study (MAAS). ${ }^{28}$ This population based study focuses on determinants of normal cognitive ageing and covers the full adult life-span of initially healthy individuals. Normative data from this study were stratified according to age, sex, and educational level. Impairment was defined as a score below the 10th percentile of the control group from MAAS; this cutoff is in line with clinical practice.

\section{Computed tomography}

The following features were recorded from the CT scan: side of the symptomatic infarct (left or right hemisphere); stroke type (lacunar or territorial infarct); presence of white matter lesions; presence of silent infarcts; and brain atrophy (for definitions see de Jong et $a^{27}$ ). White matter lesions were defined as focal or diffuse hypodensities in the periventricular or deep white matter, not involving the cortex, with ill defined margins differentiating them from infarction. ${ }^{29}$ The presence of white matter lesions around frontal or occipital ventricular horns or in the centrum semi ovale was rated separately. No effort was made to quantify the degree of white matter lesion density in these different sites, as this might be influenced by the tuning of the scanning and a certain degree of variability in the procedure of making hard copies of the scans. Silent brain infarction was defined as a low density area on the CT scan, compatible with infarction but without a history of stroke (as noted from the patient's history, from the family, or any other accessible information).
Also, the symptoms of the stroke at entry into the study had to be anatomically incompatible with such silent infarcts. Old infarcts can usually be distinguished from new ones because they are more hypodense, and there may be signs of surrounding tissue loss such as retraction of brain structures towards the infarct. The degree of atrophy was scored in a semiquantitative way (none, mild, moderate, and severe), according to the criteria of Leys et al. ${ }^{30}$ In short, CT scans of four patients were selected by three experts during a consensus meeting as example scans for the four categories: no, mild, moderate, or severe brain atrophy. The CT scans of the study patients were graded into one of these categories by visual comparison with the example scans. Silent infarcts or white matter lesions, or both were defined as "pre-stroke cerebrovascular damage". Two neurologists examined the CT scans independently. They were unaware of the neurological signs and the neuropsychological data. In case of a difference, consensus was reached by discussion. Interrater agreement (consensus reached by discussion was left out) of the classification of patients by stroke features on CT scan was excellent, with $\kappa=0.88$ for symptomatic side, 0.85 for type of stroke, 0.60 for white matter, 0.79 for silent infarcts, and 0.69 for atrophy.

\section{Patient groups}

Cognitive functioning was assessed using a neuropsychological test battery described elsewhere. ${ }^{13}$ Memory, mental speed, interference susceptibility, orientation, language, praxis, and abstract thinking were assessed based on the criteria of Roman et al. ${ }^{31}$

"Dementia" was diagnosed independently by a neuropsychiatrist and a neuropsychologist according to the DSM IV criteria, based on all available data such as a questionnaire about daily functioning, ${ }^{32}$ clinical information from a neuropsychologist, and cognitive profile. In five patients there was disagreement about the final diagnosis and these patients were classified as not demented. "Vascular MCI" was diagnosed when patients had at least one cognitive deficit. Our definition of MCI is somewhat broader than the traditional one of Petersen et al, which focused on amnestic disorders. We used their amplified criteria. ${ }^{33}{ }^{34}$ The group "vascular cognitive impairment" (VCI) had patients with both dementia or vascular MCI. Patients without cognitive disorders were assigned to the "no cognitive disorder" group. At each assessment, patients were re-evaluated for cognitive deficits and reassigned to one the four groups (dementia, VCI, vascular MCI, or no cognitive disorder) independent of the classification at other assessments.

\section{Statistical analysis}

Statistical analyses were performed using SPSS version 10. Demographic and CT features were compared for three different models: (i) patients with dementia versus patients without cognitive deficits; (ii) patients with VCI versus patients without cognitive deficits; and (iii) patients with vascular MCI versus patients without cognitive deficits.

For categorical variables $\chi^{2}$ and Fisher's exact test were used; a two-sample Student's $t$-test was used for continuous variables. Logistic regression analyses were conducted to determine the predictability of the CT and demographic variables of dementia, VCI, and vascular MCI. Variables which distinguished $(\mathrm{p}<0.05$; two-tailed $)$ between the groups in the univariate analyses were entered in a multiple logistic regression model. If either white matter lesions or silent infarcts significantly predicted the outcome group, we entered "pre-stroke cerebrovascular damage" into the multiple logistic regression model.

Missing data were imputed according to a standard procedure as described by Tabachnick and Fidell. ${ }^{35}$ Data 
Table 1 Baseline demographic and clinical variables of the four patient groups of the study

\begin{tabular}{|c|c|c|c|c|}
\hline & Dementia & $\mathrm{VCl}$ & $\begin{array}{l}\text { Vascular } \\
\mathrm{MCl}\end{array}$ & $\begin{array}{l}\text { No cognitive } \\
\text { disorder }\end{array}$ \\
\hline Number & 17 & 142 & 125 & 34 \\
\hline Mean (SD) age & $78.2(6.6)$ & 69.0 (12.3) & $67.7(12.4)$ & $63.6(12.8)^{*}$ \\
\hline $\operatorname{Sex}(M / F)$ & $9 / 8$ & $78 / 64$ & $69 / 56$ & $23 / 11$ \\
\hline Education (L/H) & $10 / 7$ & $89 / 53$ & $79 / 46$ & $11 / 23^{*}$ \\
\hline Mean (SD) & $19.8(2.3)$ & $24.8(3.5)$ & $25.5(3.1)$ & $28.3(1.5)^{*}$ \\
\hline \multicolumn{5}{|l|}{ MMSE score } \\
\hline $\begin{array}{l}\text { Hypertension } \\
\text { (pr/ab) }\end{array}$ & $10 / 5$ & $79 / 43$ & $89 / 38$ & $18 / 13$ \\
\hline Diabetes (pr/ab) & $13 / 2$ & $104 / 20$ & $91 / 18$ & $30 / 3$ \\
\hline $\begin{array}{l}\text { Cholesterol } \\
\text { (pr/ab) }\end{array}$ & $8 / 0$ & $70 / 19$ & $62 / 19$ & $25 / 3$ \\
\hline $\begin{array}{l}\text { Heart failure } \\
\text { (pr/ab) }\end{array}$ & $10 / 4$ & $104 / 20$ & $94 / 16$ & $29 / 4$ \\
\hline $\begin{array}{l}\text { Current smoking } \\
\text { (pr/ab) }\end{array}$ & $6 / 5$ & $52 / 43$ & $46 / 38$ & $18 / 10$ \\
\hline \multicolumn{5}{|c|}{$\begin{array}{l}{ }^{*} p<.05 \\
M \text {, male; } F \text {, female; } L \text {, low; } H \text {, high; pr, presence; ab, absence; } M C l \text {, mild } \\
\text { cognitive impairment; } V C l \text {, vascular cognitive impairment. }\end{array}$} \\
\hline
\end{tabular}

imputation was performed if there was at least one other test available within a specific cognitive domain and if the missing test was administered on an earlier or later assessment period.

\section{RESULTS}

A total of 176 patients ( 101 men (57.3\%), 75 women (42.7\%), average (SD) age 67.9 (12.5) years) were examined one month after stroke (table 1). Of the included patients, 100 patients $(56.8 \%)$ had a low educational level. Mean (SD) MMSE score was 25.5 (3.5). Ninety patients (51.1\%) had no symptomatic ischaemic lesions on CT. At the time of CT evaluation, the CT scans of 11 patients $(6.2 \%)$ could not be retrieved from the radiological department archives. Clinical data were used to categorise these patients and those without a CT scan, as having lacunar or territorial brain infarction (67 were classified as lacunar, 34 as territorial). Ninety nine patients $(56.3 \%)$ had lacunar stroke and $77(43.7 \%)$ had territorial stroke. Ninety six $(54.5 \%)$ patients had a stroke in the right hemisphere, 78 (44.3\%) in the left hemisphere, and two $(1.2 \%)$ patients in both hemispheres. Thirty six $(20.5 \%)$ patients had white matter lesions, $110(62.5 \%)$ had atrophy, and 57 patients $(32.4 \%)$ had at least one silent infarct.

At six months after stroke, 4 patients $(2.3 \%)$ had died and $13(7.4 \%)$ refused to participate further, $4(2.3 \%)$ refused to be reassessed (although for this time only; they were reassessed at 12 months) and 1 patient (0.6\%) was not traceable. At 12 months after stroke, a further 5 (3.2\%) patients had died and $9(5.8 \%)$ refused to participate. Patients who did not complete the study did not differ from those who remained in the study with respect to baseline MMSE score, age, educational level, and sex. Table 1 shows the distribution of the demographic and clinical variables at baseline for the four groups.

At six months after stroke 13 patients were demented, 99 were diagnosed as vascular MCI and 42 did not had any cognitive deficits. At 12 months after stroke 14 patients were demented, 85 were diagnosed as vascular MCI and 45 did not had any cognitive deficits. At six months after stroke three patients progressed from "vascular MCI" to "dementia", and nine patients progressed from "no cognitive disorder" to "vascular MCI". At 12 months after stroke, three patients progressed from "vascular MCI" to "dementia" and seven patients progressed from "no cognitive impairment" to "vascular MCI". Patients who deteriorated were more often women $\left(\chi^{2}=4.5, \mathrm{df}=1, \mathrm{p}=0.03\right)$. The other variables (age, level of education, stroke type, side of the infarct, white matter lesions, asymptomatic infarcts, and atrophy) were not different between the patients who deteriorated and those who did not.

Older age, territorial infarct, silent infarcts, pre-stroke cerebrovascular damage, and atrophy were associated with dementia one month after stroke (table 2). At six months, older age, lower educational level, territorial infarct, and prestroke cerebrovascular damage were associated with dementia. At 12 months, the same variables plus silent infarcts were associated with dementia (table 2).

At one month after stroke, lower educational level and territorial infarcts were associated with VCI; at six months older age, lower educational level, territorial infarct, and atrophy were associated with VCI; and at 12 months older age, female sex, lower educational level, white matter lesions, pre-stroke cerebrovascular damage, and atrophy were associated with VCI (table 3).

At one month after stroke, lower educational level and territorial infarcts were associated with vascular MCI; at six months older age, lower educational level, and territorial infarct were associated with vascular MCI; and at 12 months older age, female sex, lower educational level, white matter lesions, and pre-stroke cerebrovascular damage were associated with vascular MCI (table 4).

In all the univariate analyses, age was also graded in other categories $(60 v<60 ; 70 v<60,80 v<60)$. This did not change the associations.

Since the number of regression analyses was quite large (nine variables, three measurements periods and three groups) resulting in 81 analyses, it could be argued to correct

Table 2 Patients with dementia compared with patients without a cognitive disorder: univariate analyses

\begin{tabular}{|c|c|c|c|c|c|c|c|c|c|c|c|c|}
\hline & \multicolumn{4}{|c|}{1 month post stroke } & \multicolumn{4}{|c|}{6 months post stroke } & \multicolumn{4}{|c|}{12 months post stroke } \\
\hline & $\mathrm{N}(\%)$ & OR & $\mathrm{Cl}$ & $\mathbf{p}^{*}$ & $\mathrm{~N}(\%)$ & OR & $\mathrm{Cl}$ & $\mathrm{p}^{*}$ & $\mathrm{~N}(\%)$ & OR & $\mathrm{Cl}$ & $\mathbf{p}^{*}$ \\
\hline Older age & $15(88.2)$ & 12.1 & 2.4 to 61.8 & 0.00 & $10(76.9)$ & 8.3 & 1.9 to 35.7 & 0.01 & $10(71.4)$ & 6.2 & 1.6 to 23.2 & 0.01 \\
\hline Sex (female) & $8(47.1)$ & 1.9 & 0.6 to 6.1 & 0.31 & $7(53.8)$ & 2.1 & 0.6 to 7.4 & 0.25 & $7(50.0)$ & 2.8 & 8 to 9.5 & 0.11 \\
\hline Education (low) & $10(58.8)$ & 2.9 & 0.9 to 9.9 & 0.08 & $10(76.9)$ & 7.4 & 1.8 to 31.6 & 0.01 & $10(71.4)$ & 4.1 & 1.1 to 15.2 & 0.03 \\
\hline $\begin{array}{l}\text { Stroke type } \\
\text { (territorial) }\end{array}$ & $10(58.8)$ & 4.0 & 1.2 to 13.6 & 0.03 & $9(69.2)$ & 5.6 & 1.5 to 21.8 & 0.01 & $10(71.4)$ & 4.5 & 1.2 to 16.8 & 0.02 \\
\hline Side (left) & $9(52.9)$ & 2.8 & 0.7 to 7.4 & 0.18 & $7(53.8)$ & 1.8 & 0.5 to 6.4 & 0.35 & $8(57.1)$ & 2.1 & 0.6 to 7.2 & 0.23 \\
\hline $\begin{array}{l}\text { White matter } \\
\text { lesions (pr) }\end{array}$ & $3(20.0)$ & 1.8 & 0.3 to 9.4 & 0.48 & $3(23.0)$ & 1.8 & .4 to 8.5 & 0.46 & $1(8.3)$ & 0.9 & 0.1 to 8.5 & 0.90 \\
\hline Silent infarcts (pr) & 10 (66.7) & 4.0 & 1.1 to 14.6 & 0.04 & $8(61.5)$ & 3.2 & .9 to 11.6 & 0.08 & $8(66.7)$ & 5.6 & 1.4 to 22.5 & 0.01 \\
\hline PSCVD (pr) & $11(73.3)$ & 4.8 & 1.3 to 18.5 & 0.02 & $12(80.0)$ & 6.5 & 1.6 to 26.6 & 0.02 & $8(66.7)$ & 5.6 & 1.4 to 22.5 & 0.01 \\
\hline Atrophy (pr) & $13(92.9)$ & 9.2 & 1.1 to 79.9 & 0.05 & $12(92.3)$ & 7.8 & .9 to 66.5 & 0.06 & $11(91.7)$ & 7.7 & .9 to 65.2 & 0.06 \\
\hline
\end{tabular}


Table 3 Patients with vascular cognitive impairment compared with patients without a cognitive disorder: univariate analyses

\begin{tabular}{|c|c|c|c|c|c|c|c|c|c|c|c|c|}
\hline & \multicolumn{4}{|c|}{1 month post stroke } & \multicolumn{4}{|c|}{6 months post stroke } & \multicolumn{4}{|c|}{12 months post stroke } \\
\hline & $\mathrm{N}(\%)$ & OR & $\mathrm{Cl}$ & $\mathbf{p}^{*}$ & $\mathrm{~N}(\%)$ & OR & $\mathrm{Cl}$ & $\mathbf{p}^{*}$ & $\mathrm{~N}(\%)$ & OR & $\mathrm{Cl}$ & $\mathbf{p}^{*}$ \\
\hline Older age & $79(55.6)$ & 2.0 & 0.9 to 4.4 & 0.07 & $66(58.9)$ & 3.5 & 1.7 to 7.7 & 0.00 & $58(58.8)$ & 3.5 & 1.6 to 7.4 & 0.00 \\
\hline Sex (female) & $64(45.1)$ & 1.7 & 0.8 to 3.8 & 0.18 & $54(48.2)$ & 1.7 & 0.8 to 3.5 & 0.17 & $49(49.5)$ & 2.7 & 1.2 to 5.8 & 0.01 \\
\hline Education (low) & $89(62.7)$ & 3.5 & 1.6 to 7.8 & 0.00 & $71(63.4)$ & 3.9 & 1.8 to 8.2 & 0.00 & $61(61.6)$ & 2.6 & 1.3 to 5.5 & 0.01 \\
\hline $\begin{array}{l}\text { Stroke type } \\
\text { (territorial) }\end{array}$ & $68(48.9)$ & 2.6 & 1.1 to 5.9 & 0.03 & $55(49.2)$ & 2.4 & 1.1 to 5.2 & 0.02 & $46(46.5)$ & 1.6 & 0.8 to 3.3 & 0.22 \\
\hline Side (left) & $67(47.5)$ & 1.8 & 0.8 to 4.0 & 0.14 & $51(45.9)$ & 1.3 & 0.6 to 2.8 & 0.45 & $45(45.9)$ & 1.3 & 0.7 to 2.8 & 0.42 \\
\hline $\begin{array}{l}\text { White matter } \\
\text { lesions (pr) }\end{array}$ & $32(24.4)$ & 2.3 & 0.8 to 7.2 & 0.14 & $25(24.3)$ & 1.9 & 0.8 to 5.1 & 0.19 & 25 (26.3) & 3.4 & 1.1 to 10.5 & 0.03 \\
\hline Silent infarcts (pr) & $46(35.1)$ & 1.1 & 0.5 to 2.4 & 0.85 & $36(34.9)$ & 1.1 & 0.5 to 2.3 & 0.85 & $35(36.8)$ & 1.6 & 0.7 to 3.7 & 0.23 \\
\hline PSCVD (pr) & $60(45.8)$ & 1.5 & 0.7 to 3.3 & 0.33 & $46(44.7)$ & 1.3 & 0.7 to 2.7 & 0.47 & $45(47.4)$ & 2.5 & 1.1 to 5.6 & 0.02 \\
\hline Atrophy (pr) & $93(75.6)$ & 2.2 & 0.9 to 5.1 & 0.07 & 73 (77.7) & 2.3 & 1.0 to 5.1 & 0.05 & 68 (78.2) & 2.5 & 1.1 to 5.6 & 0.03 \\
\hline
\end{tabular}

the significance level to prevent type 1 errors. However, since the adjusted $\mathrm{p}$ value would have become very small $\left(\mathrm{p}_{\text {adj. }}<0.0006\right)$, the probability of finding a significant effect at all would have been reduced to an extremely low level. Because of the explorative character of the present study, it was decided not to adjust the p level, but both interpret the significance of the statistical tests and judge whether the observed effects were clinically relevant with care.

Multivariate analyses using logistic regression were performed to identify factors that were independently associated with cognitive impairment after stroke (table 5). In model I ("dementia" $v$ "no cognitive disorder" at one month after stroke) the variables included were age, location (territorial or lacunar) infarct, pre-stroke cerebrovascular damage, and atrophy. No independent predictors of dementia could be identified. Older age, lower educational level, and territorial infarct location were independently associated with dementia at six months after stroke. Older age and pre-stroke cerebrovascular damage were independently correlated with dementia at 12 months after stroke.

In model II ("VCI" $v$ "no cognitive disorder") lower educational level and territorial infarct were independently correlated with VCI at one month after stroke. Both older age and lower educational level were independently correlated with VCI at six months after stroke. Older age was independently correlated with VCI at 12 months after stroke. In model III ("vascular MCI" $v$ "no cognitive disorder"), lower educational level and territorial infarct location were independently correlated with vascular MCI at one month after stroke. Both older age and lower educational level were independently correlated with vascular MCI at six and 12 months after stroke.

\section{DISCUSSION}

We investigated specific characteristics (stroke related and demographic) that could be related to dementia, VCI, and vascular MCI at one, six, and 12 months after stroke, with special emphasis on neuroimaging data. In all the group, older age and lower educational level were found to be important predictors after stroke. Moreover, territorial as opposed to lacunar stroke was also a predictor at one month after stroke.

Other studies of post-stroke dementia have reported similar risk factors, ${ }^{7-10} 12$ however, these studies identified several stroke related risk factors for dementia, whereas we identified only territorial infarction. Territorial infarction might be associated with cognitive impairment because of the importance of these regions for higher cerebral cognitive functioning. ${ }^{3236}$ Most studies found white matter lesions and atrophy to be independent contributors to post-stroke dementia, ${ }^{5} 810$ 37-40 whereas we did not. One reason for this discrepancy is that we used CT instead of magnetic resonance imaging which is more sensitive. However, most hospital patients with stroke have a CT on admission, and as such the data presented here are of clinical relevance. Another reason is that few patients $(20.5 \%)$ had white matter lesions in our study, whereas in other studies more than half of the patients had such lesions. ${ }^{598}$ The low number of patients with white matter lesions in our study could be a consequence of the exclusion of patients with MMSE $<15$. It is quite possible that some of these excluded patients had insidiously progressing cognitive decline before stroke, which is related to white matter lesions. ${ }^{7142}$ Thus our exclusion of patients with severe cognitive impairments may have resulted in the exclusion of patients with white matter lesions.

Table 4 Patients with vascular mild cognitive impairment, compared to patients without a cognitive disorder: univariate analyses

\begin{tabular}{|c|c|c|c|c|c|c|c|c|c|c|c|c|}
\hline & \multicolumn{4}{|c|}{1 month post stroke } & \multicolumn{4}{|c|}{6 months post stroke } & \multicolumn{4}{|c|}{12 months post stroke } \\
\hline & $\mathrm{N}(\%)$ & OR & $\mathrm{Cl}$ & $\mathbf{p}^{*}$ & $\mathrm{~N}(\%)$ & OR & $\mathrm{Cl}$ & $p^{*}$ & $\mathrm{~N}(\%)$ & OR & $\mathrm{Cl}$ & $\mathbf{p}^{*}$ \\
\hline Older age & 64 (51.2) & 1.7 & $0.8-3.7$ & 0.18 & $56(56.6)$ & 3.3 & $1.5-7.1$ & 0.00 & $48(56.5)$ & 3.2 & $1.5-6.9$ & 0.03 \\
\hline Sex (female) & $69(55.2)$ & 1.7 & $0.8-3.8$ & 0.19 & $47(47.4)$ & 1.6 & $0.8-3.4$ & 0.20 & $42(49.4)$ & 2.7 & $1.2-5.9$ & 0.01 \\
\hline Education (low) & $46(36.8)$ & 3.6 & $1.6-8.0$ & 0.02 & $61(61.6)$ & 3.6 & $1.7-7.7$ & 0.00 & $51(60.0)$ & 2.5 & $1.2-5.2$ & 0.02 \\
\hline $\begin{array}{l}\text { Stroke type } \\
\text { (territorial) }\end{array}$ & $67(53.8)$ & 2.4 & $1.0-5.6$ & 0.04 & $53(53.5)$ & 2.2 & $1.1-4.7$ & 0.04 & $49(57.6)$ & 1.3 & $0.6-2.8$ & 0.45 \\
\hline Side (left) & $58(46.8)$ & 1.8 & $0.8-3.9$ & 0.17 & 44 (44.9) & 1.3 & $0.6-2.7$ & 0.53 & $37(44.0)$ & 1.3 & $0.6-2.6$ & 0.56 \\
\hline $\begin{array}{l}\text { White matter } \\
\text { lesions (pr) }\end{array}$ & $29(25.0)$ & 2.4 & $0.8-7.5$ & 0.13 & $22(24.4)$ & 1.9 & $0.7-5.2$ & 0.19 & $24(28.9)$ & 3.9 & $1.2-12.0$ & 0.02 \\
\hline Silent infarcts (pr) & $36(31.0)$ & 0.9 & $0.4-2.1$ & 0.80 & $28(31.1)$ & 0.9 & $0.4-1.9$ & 0.79 & 27 (32.5) & 1.4 & $0.6-3.1$ & 0.47 \\
\hline PSCVD (pr) & $49(42.2)$ & 1.3 & $0.6-2.9$ & 0.55 & $36(40.0)$ & 1.1 & $0.5-2.3$ & 0.84 & $37(44.6)$ & 2.3 & $1.0-5.1$ & 0.05 \\
\hline Atrophy (pr) & 80 (73.3) & 1.9 & $0.8-4.6$ & 0.13 & $61(75.3)$ & 1.9 & $0.9-4.5$ & 0.10 & 57 (76.0) & 2.2 & $0.9-5.1$ & 0.06 \\
\hline
\end{tabular}


Table 5 Multivariate logistic regression model containing univariate significant variables

\begin{tabular}{|c|c|c|c|c|c|c|c|c|c|}
\hline & \multicolumn{3}{|c|}{ Dementia $v$ no cognitive disorder } & \multicolumn{3}{|c|}{ VCl v no cognitive disorder } & \multicolumn{3}{|c|}{ V-MCI v no cognitive disorder } \\
\hline & $\begin{array}{l}1 \text { month } \\
\text { OR (CI) }\end{array}$ & $\begin{array}{l}6 \text { months } \\
\text { OR (CI) }\end{array}$ & $\begin{array}{l}12 \text { months } \\
\text { OR (CI) }\end{array}$ & $\begin{array}{l}1 \text { month } \\
\text { OR (CI) }\end{array}$ & $\begin{array}{l}6 \text { months } \\
\text { OR (CI) }\end{array}$ & $\begin{array}{l}12 \text { months } \\
\text { OR (CI) }\end{array}$ & $\begin{array}{l}1 \text { month } \\
\text { OR (CI) }\end{array}$ & $\begin{array}{l}6 \text { months } \\
\text { OR (CI) }\end{array}$ & $\begin{array}{l}12 \text { months } \\
\text { OR (CI) }\end{array}$ \\
\hline $\begin{array}{l}\text { Older age } \\
\text { Sex } \\
\text { (female) }\end{array}$ & $\begin{array}{l}4.3 \\
(0.5 \text { to } 12.9)\end{array}$ & $\begin{array}{l}9.4^{*} \\
(1.3 \text { to } 65.7)\end{array}$ & $\begin{array}{l}3.1 \\
(0.60 \text { to } 15.6)\end{array}$ & & $\begin{array}{l}4.3^{*} \\
(1.6 \text { to } 11.3)\end{array}$ & $\begin{array}{l}3.5^{*} \\
(1.4 \text { to } 8.9) \\
1.8 \\
(0.7 \text { to } 4.8)\end{array}$ & & $\begin{array}{l}3.4^{*} \\
\text { (1.5 to } 7.8)\end{array}$ & $\begin{array}{l}3.5^{*} \\
(1.5 \text { to } 8.2) \\
1.8 \\
(0.8 \text { to } 4.4)\end{array}$ \\
\hline $\begin{array}{l}\text { Education } \\
\text { (low) } \\
\text { Location } \\
\text { (territorial) }\end{array}$ & $\begin{array}{l}2.6 \\
(0.5 \text { to } 12.9 \text { ) }\end{array}$ & $\begin{array}{l}14.7^{*} \\
(1.9 \text { to } 110.3) \\
10.6^{*} \\
(1.4 \text { to } 77.6)\end{array}$ & $\begin{array}{l}8.7^{*} \\
(1.3 \text { to } 60.3) \\
6.2 \\
(0.9 \text { to } 38.7)\end{array}$ & $\begin{array}{l}3.4^{*} \\
(1.5 \text { to } 7.6) \\
2.4^{*} \\
(1.0 \text { to } 5.7)\end{array}$ & $\begin{array}{l}4.1^{*} \\
(1.7 \text { to } 9.9) \\
2.1 \\
(0.9 \text { to } 5.1)\end{array}$ & $\begin{array}{l}2.0 \\
(0.8 \text { to } 4.8)\end{array}$ & $\begin{array}{l}4.96^{*} \\
(2.0 \text { to } 12.2) \\
3.58^{*} \\
\text { (1.3 to } 9.7)\end{array}$ & $\begin{array}{l}3.7^{*} \\
(1.6 \text { to } 8.2) \\
2.01 \\
(0.9 \text { to } 4.6)\end{array}$ & $\begin{array}{l}2.28^{*} \\
(1.0 \text { to } 5.4)\end{array}$ \\
\hline PSCVD & $\begin{array}{l}2.9 \\
(0.6 \text { to } 15.1)\end{array}$ & $\begin{array}{l}3.4 \\
(0.5 \text { to } 21.5)\end{array}$ & $\begin{array}{l}7.4^{*} \\
(1.1 \text { to } 47.2)\end{array}$ & & & $\begin{array}{l}1.9 \\
(0.7 \text { to } 5.4)\end{array}$ & & & $\begin{array}{l}1.5 \\
(0.6 \text { to } 3.8)\end{array}$ \\
\hline Atrophy & $\begin{array}{l}3.0 \\
(0.3 \text { to } 37.5 \text { ) }\end{array}$ & & & & $\begin{array}{l}1.0 \\
(0.4 \text { to } 3.0)\end{array}$ & $\begin{array}{l}1.2 \\
(0.5 \text { to } 3.2)\end{array}$ & & & \\
\hline
\end{tabular}

The studies referred to above examined dementia after stroke, and as such they neglected patients who did not meet the criteria for dementia but who nevertheless might have had cognitive impairments. Other investigators have investigated the association between cognitive disorders not restricted to dementia, and stroke related features, but few included multivariate analyses in the study design. ${ }^{17}{ }^{23-26}$ Schmidt et $a^{23}$ found multiple infarcts and temporal lobe infarction to be risk factors for cognitive disorders. Patel $e a^{26}$ reported left hemisphere infarction, older age, ethnicity, socioeconomic status, and stroke severity to be important contributors to the development of cognitive disorders after stroke. The only stroke related factor that contributed independently to VCI early after stroke in our study was territorial infarction. Unlike other studies we were able to diagnose more subtle cognitive deficits because of the use of an extensive and sensitive set of neuropsychological tests. Patients with only subtle cognitive deficits have either less brain damage or they might have brain damage in regions that are of less importance for cognitive functioning. This could explain why we found fewer associations between the CT scan features and cognitive disorders.

Although recent research has focused on post-stroke cognitive impairment not restricted to dementia, to our knowledge no studies have reported on cognitive disorders without dementia. We found that soon after stroke, territorial infarction, older age, and lower educational level were predictors of vascular MCI. The univariate analyses revealed that pre-existing vascular brain damage (white matter lesions or silent infarcts) became more important later. This could mean that with increasing time after the stroke the influence of the initial infarct decreases, and the influence of preexisting brain damage becomes more important. In most stroke patients white matter lesions or silent infarcts progress over time, despite standard treatment, and consequently, cognitive functioning may decline..$^{29}{ }^{43-45}$ We did not investigate whether the patients with cognitive decline had progressively increasing brain damage at six and 12 months, but in the future we plan to investigate the relation between accumulating brain damage and cognitive decline.

There are certain limitations to this study. First, only one third of the total stroke population admitted to the hospital during the inclusion period was included in the study. However, our series was not affected by referral bias, because the University Hospital Maastricht is the only hospital in that region. Secondly, to perform valid analyses with sufficient power we imputed data for some patients with missing data. This was done by an experienced neuropsychologist who decided, on the basis of the available data and the patients' neuropsychological profile, how to impute the data. Although this method is subjective, a comparison of this method with one based on regression analyses did not yield different results. We also compared for all analyses the database with the imputed data with the database without the imputed data and all conclusions were unchanged. Thirdly, because we excluded patients with MMSE $<15$ we may have excluded patients with specific stroke related features such as territorial infarction or white matter lesions. However, we studied cognitive decline in those patients for whom such decline might be most relevant, namely patients without any prior severe cognitive problems. Fourthly, infarct site and size might be relevant factors to study as independent predictors for post-stroke cognitive impairment. However, the fact that only about one half of the patients had an infarct visible on $\mathrm{CT}$, which was mainly due to early scanning, forestalled such analysis. Another study also found visible lesions on CT within 48 hours after stroke in $50 \%$ of the patients. ${ }^{46}$ Lastly, our study design could not rule out that some patients with dementia might have had mixed type instead of vascular type. Although white matter lesion are generally held to be caused by vascular insufficiency, they can also occur in patients with dementia of Alzheimer's type. ${ }^{47}$ However, by excluding patients with MMSE $<15$ and patients with dementia before stroke, we made the likelihood of including such patients low.

Despite its limitations, this study is the first to investigate the relation between early CT scan features and post-stroke cognitive impairment on a longitudinal basis. Territorial infarction, older age, and lower educational level are important risk factors for cognitive disorders after stroke. Pre-stroke damage, as diagnosed from the CT scan, is probably related to cognitive disorders later after stroke.

\section{ACKNOWLEDGEMENTS}

We would like to thank I Winkens for the neuropsychological assessment, Prof Dr J Jolles for the imputation of missing data, and R Ponds for his contribution in the diagnosis of dementia.

\section{Authors' affiliations}

S M C Rasquin, F R J Verhey, R Lousberg, Research Institute Brain and Behaviour, Department of Psychiatry and Neuropsychology, University of Maastricht/University Hospital Maastricht, Maastricht, the Netherlands

R J van Oostenbrugge, J Lodder, Research Institute Brain and Behaviour, Department of Neurology, University of Maastricht/ University Hospital Maastricht, Maastricht, the Netherlands 
This study was supported by grants from the Adriana van RinsumPonssen foundation.

Competing interests: SR has been reimbursed by SWOL for attending a conference.

\section{REFERENCES}

1 House A, Dennis M, Warlow C, et al. The relationship between intellectual impairment and mood disorder in the first year after stroke. Psychol Med 1990;20:805-14

2 Rockwood K, Wentzel C, Hachinski V, et al. Prevalence and outcomes of vascular cognitive impairment. Vascular Cognitive Impairment Investigators of the Canadian Study of Health and Aging. Neurology 2000;54:447-51.

3 Censori B, Manara O, Agostinis C, et al. Dementia after first stroke. Stroke 1996:27:1205-10

4 Charletta D, Gorelick PB, Dollear TJ, et al. CT and MRI findings among African-Americans with Alzheimer's disease, vascular dementia, and stroke without dementia. Neurology 1995;45:1456-61.

5 Lin RT, Lai CL, Tai CT, et al. Cranial computed tomography in ischemic stroke patients with and without dementia-a prospective study. Kaohsiung J Med Sci 1998;14:203-11.

6 Loeb C, Gandolfo C, Bino G. Intellectual impairment and cerebral lesions in multiple cerebral infarcts. A clinical-computed tomography study. Stroke 1988:19:560-5.

7 Henon H, Durieu I, Guerouaou D, et al. Poststroke dementia: incidence and relationship to prestroke cognitive decline. Neurology 2001;57:1216-22.

8 Desmond DW, Moroney JT, Paik MC, et al. Frequency and clinical determinants of dementia after ischemic stroke [in process citation]. Neurology 2000:54:1124-31.

9 Pohjasvaara T, Mantyla R, Salonen O, et al. How complex interactions of ischemic brain infarcts, white matter lesions, and atrophy relate to poststroke dementia. Arch Neurol 2000;57:1295-300.

10 Pohjasvaara T, Mantyla R, Salonen O, et al. MRI correlates of dementia after first clinical ischemic stroke. J Neurol Sci 2000;181:111-17.

11 Tatemichi TK, Desmond DW, Paik M, et al. Clinical determinants of dementia related to stroke. Ann Neurol 1993;33:568-75.

12 Barba R, Martinez-Espinosa S, Rodriguez-Garcia E, et al. Poststroke dementia: clinical features and risk factors. Stroke 2000;31:1494-501.

13 Rasquin SMC, Verhey FRJ, Lousberg R, et al. Vascular cognitive disorders. Memory, mental speed and cognitive flexibility after stroke. J Neurol Sci 2002;203-204(C): 115-19.

14 Ballard C, Stephens S, Kenny R, et al. Profile of neuropsychological deficits in older stroke survivors without dementia. Dement Geriatr Cogn Disord 2003;16:52-6

15 Bowler JV, Hadar U, Wade JP. Cognition in stroke. Acta Neurol Scand 1994:90:424-9.

16 Leskela $M$, Hietanen $M$, Kalska $H$, et al. Executive functions and speed of mental processing in elderly patients with frontal or nonfrontal ischemic stroke. Eur J Neurol 1999;6:653-61

17 Madureira S, Guerreiro M, Ferro JM. Dementia and cognitive impairment three months after stroke. Eur J Neurol 2001;8:621-7.

18 Wentzel C, Rockwood K, MacKnight C, et al. Progression of impairment in patients with vascular cognitive impairment without dementia. Neurology 2001;57:714-16

19 Ingles JL, Wentzel C, Fisk JD, et al. Neuropsychological predictors of incident dementia in patients with vascular cognitive impairment, without dementia. Stroke 2002:33:1999-2002

20 Ebly EM, Hogan DB, Parhad IM. Cognitive impairment in the nondemented elderly. Results from the Canadian Study of Health and Aging. Arch Neurol 1995;52:612-19.

21 O'Brien JT, Erkinjunti T, Reisberg B, et al. Vascular cognitive impairment. Lancet 2003;2:89-98.

22 DeCarli C. Mild cognitive impairment: prevalence, prognosis, aetiology, and treatment. Lancet 2003;2:15-21.
23 Schmidt R, Mechtler L, Kinkel PR, et al. Cognitive impairment after acute supratentorial stroke: a 6-month follow-up clinical and computed tomographic study. Eur Arch Psychiatry Clin Neurosci 1993;243:11-15.

24 Elwan O, Hashem S, Helmy AA, et al. Cognitive deficits in ischemic strokes: psychometric, electrophysiological and cranial tomographic assessment. J Neurol Sci 1994; 125:168-74.

25 Kase CS, Wolf PA, Kelly-Hayes $M$, et al. Intellectual decline after stroke: the Framingham Study. Stroke 1998;29:805-12.

26 Patel MD, Coshall C, Rudd AG, et al. Cognitive impairment after stroke: clinical determinants and its associations with long-term stroke outcomes. J Am Geriatr Soc 2002;50:700-6.

27 de Jong G, van Raak L, Kessels F, et al. Stroke subtype and mortality. a followup study in 998 patients with a first cerebral infarct. J Clin Epidemiol 2003;56:262-8.

28 Jolles J, Houx PJ, van Boxtel MPJ, et al. The Maastricht Aging Study: Determinants of cognitive aging. Maastricht: Neuropsych Publishers, 1995.

29 van Zagten M, Boiten J, Kessels F, et al. Significant progression of white matter lesions and small deep (lacunar) infarcts in patients with stroke. Arch Neurol 1996;53:650-5.

30 Leys D, Pruvo JP, Petit $\mathrm{H}$, et al. [Maladie d'Alzheimer: anlyse statistique de resultats du scanner X]. Rev Neurol (Paris) 1989;145:134-9.

31 Roman GC, Tatemichi TK, Erkinjuntti T, et al. Vascular dementia: diagnostic criteria for research studies. Report of the NINDS-AIREN International Workshop [see comments]. Neurology 1993:43:250-60.

32 Teunisse S, Derix MM. [Measurement of activities of daily living in patients with dementia living at home: development of a questionnaire] [see comments]. Tijdschr Gerontol Geriatr 1991;22:53-9.

33 Petersen RC, Doody R, Kurz A, et al. Current concepts in mild cognitive impairment. Arch Neurol 2001;58:1985-92.

34 Petersen RC, Smith GE, Waring SC, et al. Mild cognitive impairment: clinical characterization and outcome. Arch Neurol 1999;56:303-8.

35 Tabachnick BG, Fidell LS. Using multivariate statistics. Boston: Allyn \& Bacon, 2001.

36 Tatemichi TK, Desmond DW, Paik M, et al. Clinical determinants of dementia related to stroke. Ann Neurol 1993;33:568-75.

37 Liu CK, Miller BL, Cummings JL, et al. A quantitative MRI study of vascular dementia. Neurology 1992;42:138-43.

38 Pennese F, Del Re ML, Esposito F, et al. Clinical and tomographic findings in vascular dementia. Aging (Milano) 1994;6:57-64

39 Pohjasvaara T, Mantyla R, Salonen O, et al. How complex interactions of ischemic brain infarcts, white matter lesions, and atrophy relate to poststroke dementia. Arch Neurol 2000;57:1295-300.

40 Henon H, Pasquier F, Durieu I, et al. Medial temporal lobe atrophy in stroke patients: relation to pre-existing dementia. J Neurol Neurosurg Psychiatry 1998;65:641-7.

41 Pasquier F, Leys D. Why are stroke patients prone to develop dementia? J Neurol 1997;244:135-42.

42 Pasquier $\mathbf{F}$, Henon $\mathrm{H}$, Leys $\mathrm{D}$. Relevance of white matter changes to pre- and poststroke dementia. Ann N Y Acad Sci 2000;903:466-9.

43 Bernick C, Kuller L, Dulberg C, et al. Silent MRI infarcts and the risk of future stroke: the cardiovascular health study. Neurology 2001;57:1222-9.

44 Meyer JS, Obara K, Muramatsu K, et al. Cognitive performance after small strokes correlates with ischemia, not atrophy of the brain. Dementia 1995;6:312-22.

45 Vermeer SE, Prins ND, den Heijer T, et al. Silent brain infarcts and the risk of dementia and cognitive decline. N Engl J Med 2003;348:1215-22.

46 Wardlaw JM, West TM, Sandercock PA, et al. Visible infarction on computed tomography is an independent predictor of poor functional outcome after stroke, and not of haemorrhagic transformation. J Neurol Neurosurg Psychiatry 2003:74:452-8.

47 Englund $E$, Brun A, Alling C. White matter changes in dementia of Alzheimer's type. Biochemical and neuropathological correlates. Brain $1988 ; 111(\mathrm{Pt} 6): 1425-39$. 